MedieKultur | Journal of media and communication research | ISSN 1901-9726

Article

\title{
SunDial:
}

\section{Embodied informal science education using GPS}

\author{
Megan Halpern, Max Evjen, Dan Cosley, \\ Michael Lin, Stephen Tseou, Erica Horowitz, \\ S. Tejaswi Peesapati \& Geri Gay
}

MedieKultur 2011, 50, 48-65

Published by SMID | Society of Media researchers In Denmark | www.smid.dk The online version of this text can be found open access at www.mediekultur.dk

Science centers serve a number of goals for visitors, ideally providing educational, social, and meaningful experiences. This paper presents a case study in which we used guidelines for informal science education (ISE) experiences recently released by the National Science Foundation and the National Research Council to inform the design of SunDial, a handheld application developed for families to use at a science center. Inspired by the idea of geocaching, the high-tech GPS treasure hunting game, SunDial asks families to use a single handheld device to find and participate in a series of learning modules located around the museum. Observations of 10 families suggest that SunDial supports rich informal science education experiences, provides insights about the effect of single handheld devices on family interaction patterns, and demonstrates the value of navigation as an educational experience. Our experience also shows that using the guidelines to inform the design process for ISE programs proved valuable, tying features of the technology to educational and social goals, and giving evidence that explicit attention to these guidelines can improve ISE experiences and technologies. 


\section{Introduction}

Individuals, couples and families attend museums for a variety of reasons, including achieving educational goals, having social experiences, and deriving meaning from their visits (Bell \& Gemmell, 2009). Science centers serve similar goals, but where traditional museums "emphasize cultural heritage through objects of intrinsic value", science and technology centers "aim to both enlighten and entertain through contemporary, participatory exhibits" (Rennie \& McClafferty, 1996, p. 54).

Science, art, and history museums, to varying degrees, have all embraced technology to support these museum experiences. Whereas traditional art and history museums tend to adhere to being arbiters of culture, science and technology museums "are predicated on the notion of visitor interactions. As a result, these ecological niches seem to have been a lot quicker to adopt in-museum technology" (Bell, 2002, p. 11). In science museums, dioramas are being replaced by multimedia, touch screens, handheld guides, and kiosks, while science centers like the Exploratorium in San Francisco are using RFID and other technologies to extend the experience beyond the time spent at the center (Hsi \& Fait, 2005). However, the foregrounding of educational goals sometimes leads to a focus on information at the expense of social and experiential aspects of learning (Chipman et al., 2006) that recent guidelines suggest are as important as the transmission of scientific concepts (Bell, Lewenstein, Shouse, \& Feder, 2009; Friedman, 2008).

We wanted to develop a science center technology that supports these social and experiential goals while still providing informal science education (ISE) experiences. The prototype we developed, SunDial, is an interactive handheld guide that leverages the idea of geocaching by guiding families to find and complete a number of scientific activities located in the vicinity of a science museum. Geocaching is a socially driven leisure activity in which users build and share "caches", which others seek using Global Positioning Satellite (GPS) technologies (for more information, see Chavez, Schneider, \& Powell, 2004; Clough, Jones, McAndrew, \& Scanlon, 2008; O'Hara, 2008). Sundial helps achieve a balance between educational, social, and experiential goals by incorporating explicit social and reflective elements, including combining social interaction (Rennie \& McClafferty, 1996) through the collaborative use of a single handheld device, embodiment (Dourish, 2004) through a dance element, and opportunities to reflect on everyday phenomena throughout the program. Below, we describe how its design and features were informed by recent research on guidelines for developing ISE experiences, and evaluate it based on observations of ten families using the prototype at a science center in a small university town.

\section{Supporting informal science education}

Recent reports from the National Science Foundation (Friedman, 2008) and the National Research Council (Bell et al., 2009) provide guidelines and criteria, recommended by an advisory panel of experts in science education (both informal and formal) and science com- 
munication, for supporting informal science education. These guidelines include the need to support awareness, engagement, knowledge, skills, and attitudes about science. In the report, Bell et al. (2009) suggest six aspects of informal science learning, or "strands", that have been observed in ISE environments and explain how social and interactive experiences in science centers create unique and rich understandings of the process and products of science. The six strands are as follows (Bell et al., 2009, p. 16):

Strand 1: Experience excitement, interest, and motivation to learn about phenomena in the natural and physical world.

Strand 2: Come to generate, understand, remember, and use concepts, explanations, arguments, models and facts related to science.

Strand 3: Manipulate, test, explore, predict, question, observe, and make sense of the natural and physical world.

Strand 4: Reflect on science as a way of knowing; on processes, concepts, and institutions of science; and on their own process of learning about phenomena.

Strand 5: Participate in scientific activities and learning practices with others, using scientific language and tools.

Strand 6: Think about themselves as science learners and develop an identity as someone who knows about, uses, and sometimes contributes to science.

These strands provide a framework for assessing and evaluating how informal environments can "stimulate science interest, build learners' scientific knowledge and skill, and-perhaps most importantly-help people to learn to be more comfortable and confident in their relationship with science" (Bell et al., 2009, p. 25). The National Science Board's 2007 report on the critical needs in Science, Technology, Engineering and Mathematics (STEM) education calls for the need for coherence in informal science education, an adequate supply of well prepared and effective STEM teachers, and coordination of formal and informal environments to enhance curriculum and teacher development (National Science Board, 2007). The strands have been developed to help facilitate that coordination.

We suggest that in addition to helping researchers and museum curators understand and evaluate informal science education, the strands can also be used as tools for designers looking to build technology to support ISE. In this case study, we set out to develop a pilot program that would use iPhones to encourage the ways of thinking described by the strands. Throughout the design process, the team focused on using the six strands as inspiration and guidance in developing a product that would encourage the informational, social, and experiential/meaning-making aspects of museum going (Bell \& Gemmell, 2009). Strand 2 and to some extent 3 point to the more traditional informational goals of ISE; Strands 4 and 6 call out experiential aspects; Strand 5 is explicitly social; and Strand 1 is a kind of meta-need that might be easiest to achieve if the other goals are accomplished. The strands are a starting point for operationalizing the kinds of activities and design elements technologies for ISE in museums need in order to accomplish their educational and social goals, and our hope was that by heeding the strands we would support both ISE and 
an appropriate balance of education, social, and meaningful experiences. For example, the strands (specifically strands 3, 4, and 6) suggest that one path to effective informal science education provides experiences that cast learners in the role of scientists, teaching valuable skills like observation, deduction, and collaboration. As we designed SunDial, we looked for ways in which children and families at a museum could engage in experiences that would allow them to observe and describe things in the same manner as a scientist.

\section{SunDial}

SunDial was developed as an iPhone application designed to for the Sciencenter in Ithaca, New York, a small university town that is home to Cornell University and Ithaca College, and near Tompkins County Community College. The median income is $\$ 27,939$. It has an extremely high number of college-educated adults compared to the rest of New York State and to similar towns throughout the nation. According to the 2000 United States census, the city population was 29,287 , but enrollment in local universities during the school year puts the temporary population at approximately 75,000 . The Sciencenter is a small handson science museum that caters to children and families in Ithaca and the surrounding areas.

We chose iPhones as our platform because of their portability, location-awareness, and multimodal input capabilities using text, pictures, and audio. These rich, expressive tools for learning and inquiry allowed us to explore novel ways to implement the strands. Handheld devices have a long tradition of supporting informal learning in museums; in fact, handhelds were the first visitor technology used in a museum (Tallon \& Walker, 2008). These handheld systems support both educational and social purposes of museum-going by providing information, shared experience, and collaborative activities (e.g., Chipman et al., 2006; Cosley et al., 2009; Grinter et al., 2002; Hope et al., 2009; Hsi \& Fait, 2005; ThomSantelli et al., 2006).

Science museums, in particular, often make creative use of handheld technologies to support informal science education. The Exploratorium in San Francisco teamed up with HP Labs to create the Electronic Guidebook, a wireless device that interacted with existing Exploratorium exhibits and allowed visitors to access customized web pages from desktop computers at home (Bell, 2002). The Minpaku Navi project provided evidence that families' use of handheld devices in museums facilitated education about exhibits, as well as conversations that contributed to the sense of museum as a social leisure space (Hope et al., 2009).

Handhelds have also been used beyond the walls of the museum to support ISE. The Tangible Flags project demonstrated the potential value of using RFID-enabled markers to support field trips for young children (Chipman et al., 2006), while Parr et al. (2004) found that middle school students more easily and accurately recorded field data with pen based handhelds than with paper workbooks. This evidence regarding the use of handheld devices in and around museum settings suggests a need for further exploration of how current technology can be utilized to promote both educational and social benefits. 
SunDial makes use of several features of the iPhone to create opportunities for engagement with science among museum visitors. Using GPS navigation as a learning tool, while at the same time building on the interface design standards of the iPhone and the practice of geocaching, SunDial provides structured, interactive activities at designated geographical points. Each of four learning modules presents a unique challenge that calls for different ways of engaging with the device and with the physical world, different kinds of observations and interactions with other SunDial users, and different ways of thinking about and reflecting on science-related issues.

These modules, and other features of the software, were developed by thinking about how the possibilities offered by handheld technologies could follow the NSF and NRC guidelines on supporting informal science education. For instance, Strand 1 focuses on interest and excitement. The program's use of a mobile technology and casting the learning experience as a treasure hunt facilitates "visitors' enjoyment and learning in ways that would be extremely difficult if not impossible to provide through other media" (Gammon \& Burch, 2008, p. 35). Strand 2 focuses on the use, memorization, and generation of concepts, explanations, arguments, and models related to science. Each module of the program encourages families to create explanations and arguments for the phenomena they observe. Strand 3 focuses on the skills of inquiry and reasoning and suggests that "asking and answering questions and evaluating evidence are central to doing science and to successfully navigating through life." Throughout the program, we designed a series of questions that could be answered through voice, text, and picture taking.

Strand 4 focuses on reflecting on science as a way of knowing. We designed an ending to the program that entailed a guided reflection experience that provided the participants with the support that allowed them to understand their role in scientific processes. Strand 5, which focuses on learners participating as groups in scientific endeavors, aims to "[change] the inaccurate stereotype of the lone scientist working in isolation in his laboratory to the accurate perception of groups of people interacting with each other to achieve greater understanding of a problem or phenomenon [which] is critical to creating a positive attitude toward science learning." We designed the program for families, which automatically placed participants in working groups. Finally, SunDial is designed to address Strand 6, which focuses on learners' agency: "Not only can educational activities develop the knowledge and practice of individuals and groups, they can also help people develop identities as science learners and, in some cases, as scientists" (Bell et al., 2009, p. 52). Questions at the beginning and end of the program were designed to make explicit the connections between the activities in which the participants engaged and the activities in which scientists engage.

The above list is not exhaustive; its goal is to provide examples of how each of the strands could be used to think about choices at all levels of detail in designing ISE experiences, from the choice of an appropriate venue of ISE, to the selection of learning activities, to the design of specific questions and interactions. In the remainder of the paper, we would like to focus on how the strands can help designers think about the ways in which features of new tech- 
nologies, such as mobility, location awareness, and multimodal input, are likely to be useful for supporting ISE experiences. We will concentrate on four main design features that we thought were effective examples of mapping the strands to the capabilities of the iPhone:

1. Moving outside the museum. In the studies cited above (Bell, 2002; Hope et al., 2009; Chipman et al., 2006; Parr 2004), handhelds' mobility allowed them to be used in the field as data collection devices (Tangible Flags), and in the museum as informational aids and social devices (the Electronic Guidebook and Minpaku Navi). We hoped to provide an experience that facilitated data collection and engagement with natural phenomena while at the same time providing information consistent with the exhibits inside the museum. In addition, we hoped that by moving the experience outside the walls of the museum, we could bring the kinds of enrichment found in museums to outside activities and the energy and excitement of outdoor activities to museum learning, helping participants to experience the excitement and engagement about science described in Strand 1.

2. Guided autonomy. We used GPS-based navigation and "hunting" for activities to encourage users to perceive SunDial as an autonomous adventure instead of a set series of learning activities. By generating a sense of control over the experience, while providing clear guidance through the interface, we hoped to allow space for users to explore on their own and experience their own agency with science (Strand 6), while providing enough guidance so that they did not become lost or discouraged.

3. Learning through navigation. The process of navigation itself can have valuable educational uses. The NRC's report Learning to Think Spatially-GIS as a Support System in K-12 Education (Downs \& DeSouza, 2006, p. 94) recommends that spatial thinking be recognized as a fundamental part of $\mathrm{K}-12$ education due to its importance as a problem-solving tool in many different disciplines. "Spatial thinking is powerful and pervasive, underpinning everyday life, work, and science" (Downs \& DeSouza, 2006, p. 94). By providing families with a GPS device, the participants experienced using a tool of science in practice with others (Strand 5).

4. Two-way engagement with science. Many museum technologies, handheld and otherwise, focus on a one-way transfer of information. We hoped to use the input features of the iPhone to create a fun, hands-on experience. By incorporating scientific reasoning activities that engaged participants, we hoped SunDial would encourage excitement not just for the experience, but for the scientific concepts embedded in the experience. This goal relates to Strand 1 (engagement), Strand 4 (reflection on science as a way of knowing), and Strand 5 (participate in scientific activities). In addition, part of the NRC's report suggests that learners should take on the role of the scientist (Strand 6). Observation is at the heart of the scientific process, and using handheld devices to formalize the observation process helps learners to step into this role. Bringing SunDial out of the museum and into the world provides opportunities for deep observation of natural phenomena present and accessible in everyday life. 

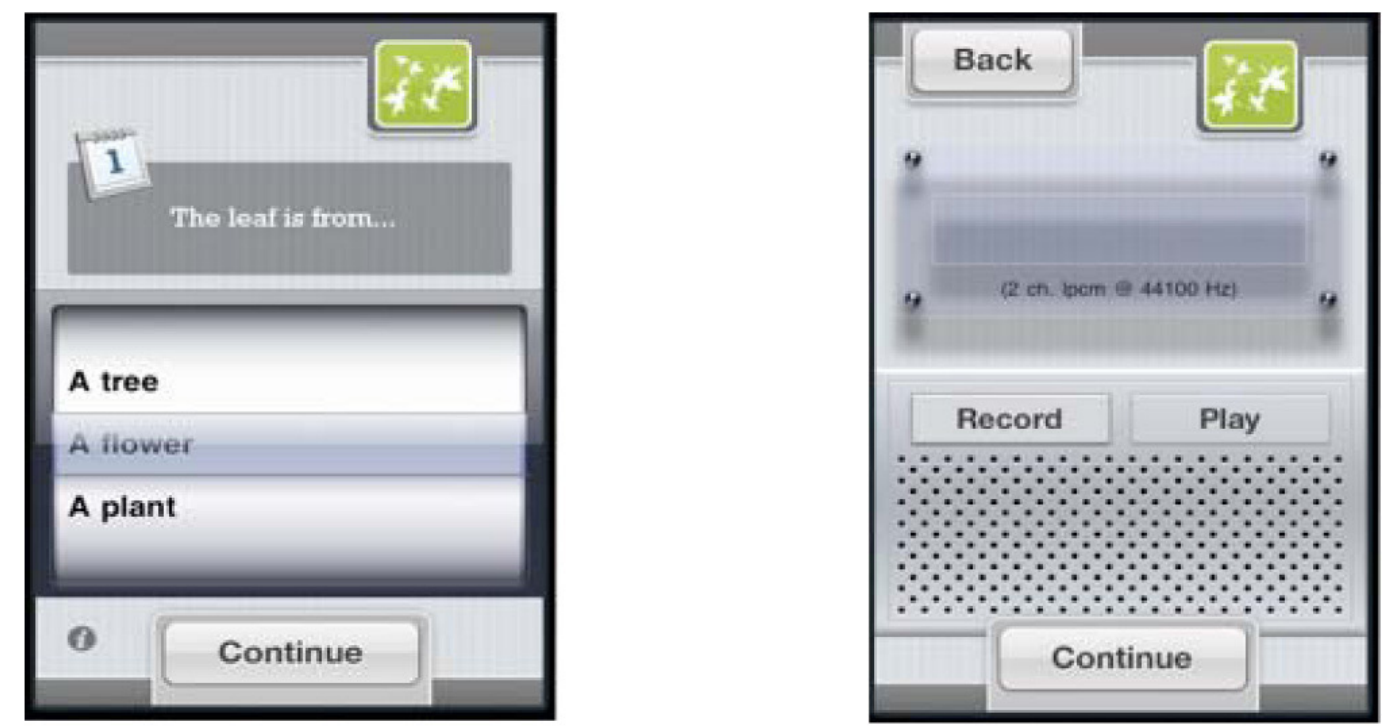

Figure 1. Views of the phone for multiple choice and audio recorded answers.

\section{The SunDial application}

The SunDial prototype is an iPhone application that can be used outside without wireless access. Users first download the software to their device. In our evaluation, the users borrowed a pre-loaded phone at the Sciencenter. The phone then guided them through a series of learning modules, each of which asked the group to navigate to a location, to engage in observations and activities around a science-related topic, and to record observations and answer questions using the device. The device called these observations "field notes", framing itself as a scientist's tool for observation, rather than an interface or a game. Asking people to record their reactions also increased the system's interactivity and focused user's attention on observing the world.

The prototype started with a Tutorial module that taught families how to use the device. It then led them on three challenges. The first module, the Sundial (Figure 2), took learners to a giant sundial located just outside the museum. They were asked to photograph the shadow (or, on cloudy days, where they thought the shadow would be) and to answer questions about how the seasons affect the shadow. The second module, the Leaf, directed families to a nearby trail surrounded by bushes, flowers, and trees, and asked them to choose a leaf. They were asked about the shape, color, smell, and texture of the leaf, instructed to draw it, and finally asked to answer questions about why leaves are shaped as they are. Finally, the third module, Water, took place on the bank of a nearby stream. A dancer led them through a series of movements, worked with the phone to prompt families to think about how water moves, and asked them to move and pose like water. After the third module, the phone directed the families to a location where they reflected on their experience with a facilitator, completed a survey, and returned their phones. 
The interface was designed to be simple. For navigation, when the phone is turned horizontally, a map indicates the location of the next activity (green pin) and their current location (blue dot). Learners used several media to record observations, including text input, audio recordings (Figure 1), and pictures. Using multiple media supported a variety of activities and learning styles while reducing the need to type on a small phone keyboard.

The design of SunDial went through several iterations, both on paper and in the field. Tests with early paper prototypes suggested the device should possess some human qualities to invite user interaction. To accomplish this, we framed the device as a guide who spoke to itself in the first person and provided "fun facts" as a kind of offhand observation. These design choices helped the device take on some qualities of a human guide, and though it was not quite as engaging as a human, we hoped the "character" would be helpful in increasing the system's perceived interactivity.

Developing an application that could appeal to a wide variety of ages was also a challenge, from providing simple, clear instructions to choosing appropriate topics and difficulty levels. Based on several rounds of prototyping, we converged on a design that was most effective for families with children ages 8 to 12. The program focused on this particular age group as these are the ages that the New York State Curriculum and Instruction Guide in Science (2009) indicates should be learning about interactions between air, water, and land, and about seasonal changes. The reflection facilitator's experience working with children in that age group and older indicated that it is also an age group that tends to value movement and more readily engages in family activities than Junior High or High School children. In addition, the Sciencenter's target audience is preschool through elementary and middle school children, and most people attend the Sciencenter as family groups, which meant that particular age group and their families were most likely to be available for recruitment for the study.

\section{Methods}

To see how well SunDial accomplished its design goals and gauge its potential for supporting informal science education, we observed ten families (38 people) using the prototype. Of the 36 who responded to demographic questions, three participants were aged 1-7, sixteen were 8-12, seven were 13-17, and ten adults ranged between 22 and 64 years old. Twenty children were female, five were male, while seven adults were female, four were male. Although our analysis is based on observations and data from all the participants, we chose three representative families: the Reids, the Jones, and the Philips ${ }^{1}$. The Reids were an African American family consisting of a mother with her two daughters, approximately 10 and 12 years old, along with the younger daughter's two friends of approximately the same age. The Jones were a Caucasian family with a mother and father, a son approximately 9 years old, and daughter approximately 5 years old. The Philips were an Indian family consisting of a father and two daughters, each daughter approximately 10 to 12 years old. 
We collected multiple streams of data. Observers at each module took notes about families' group dynamics and their interactions with the device. Video cameras were used to capture behavior at the Sundial and Water module. Participants' field notes (audio, photo, and typed entries) were recorded on the device itself. Pre-surveys asked for demographic information and familiarity with technology, including GPS navigation. At the end of the program, the children were interviewed about the experience in a reflection session, a questionnaire asked about everyone's experiences using the handheld, and parents were also asked about their perceptions of their children's activities. The final module also encouraged visitors to reflect on science as a way of knowing and on their own learning process, indicators of Strands 4 and 6 of the NRC report (Bell et al., 2009). In addition, the group discussion in the final module served both to help us gauge participants' reactions and to help participants reflect, with the hope of supporting "personal synthesis, integration and appropriation of knowledge" (Boud, Keogh \& Walker, 1985).

We analyzed the data in two ways. First, five team members individually looked at the field notes written by participants and observations taken by the team while people were using SunDial, then the team members generated concept maps based on major themes and unusual occurrences. Second, two senior team members analyzed the survey data and the videos and asked professionals at the science center and the dancer who worked on the Water module to provide their own observations. The following discussion details observations about each of the four goals we established for SunDial, as well as provides other observations.

We recognize that there are limitations in an exploratory study such as this. OOur aim is to be more generative than generalizable. In this paper, we present a case study in which we provide an example for how to use the six strands of informal science education as a tool for both the design and evaluation of a museum program. Though this is a small pilot study, we believe in the value of observing participants as they complete the SunDial program, and analyzing our observations of their interactions with the app and with each other provided rich data we would have been unable to gather from surveys or other quantitative measures. We hope that further research on SunDial or similar projects will help further develop the ideas presented here.

\section{Discussion}

Below, we discuss how our participants reacted to SunDial, particularly around the four main design features presented earlier, and how these reactions indicated both engagement with science and ISE outcomes as well as aspects of the prototype that might have hindered that engagement. 


\section{Moving outside the museum}

By asking learners to navigate through and observe the physical world, SunDial deviated from the traditional museum experience, turning it into what several, including the boy in the Jones family, called "an adventure". Asking learners to actively record data provided new ways for children to interact with nature. For example, at The Leaf, families deeply studied the leaf, smelling it, describing the ridges of the leaf, sometimes in great detail.

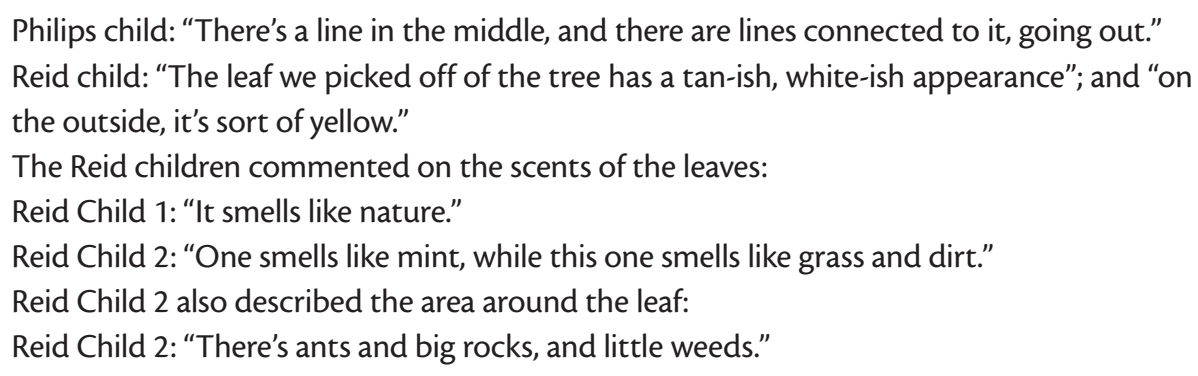

In addition to the recordings, the girls were observed holding the leaf as they drew it, looking back and forth between their drawing and the leaf, paying great attention to all of the details as they drew.

\section{Guided autonomy}

Balancing autonomy and learning goals was a concern. Geocaching, the activity that inspired SunDial, is a fully autonomous experience, in which participants choose their own destinations, provide their own GPS system, and chart their own course; caches themselves are even provided by users. Because our goal was to create meaningful learning experiences for young children, we chose a more guided approach that directed groups to four successive locations that traced around the exterior of the museum, encouraged participants to travel along a route that would steer clear of traffic in nearby streets, and that would guide participants through an iterative process that mirrored scientific discovery.

Only one participant, a thirteen-year-old boy, felt the need for an alternative to the guided program: "instead of just answering questions, try to do more, something athletic." A parent clarified his statement by saying, "It sounds like they wanted to do something more 'hands-on'." The program was ideally designed for children between eight and twelve, and considering the project team's knowledge that children older than twelve tend not to value family activities as readily as those under the age of twelve do, the fact that a thirteen year-old found it stifling was not a surprise. We also believe that had families at a science center been asked to complete the project at a higher level of autonomy, some may have lost interest rapidly. We base this prediction on observations that Sciencenter visitors who found the sundial on their own (they were not a part of our study) often failed to read the sign that explained it and did not appear to attempt to understand how it worked. In addition, in families that did not read the screens of Sundial aloud, children were more likely to 
disengage, while in families in which parents read instructions aloud, or in which the parents let the children read the instructions themselves, children appeared engaged in questioning, reasoning, and observation. This suggests that whole family engagement in instruction was valuable.

This also suggests that engaging the whole family together in making sense of the instructions and activities was important, and when this didn't happen, engagement and attention waned. The Jones' father was observed holding the phone for much of the program, rarely reading instructions aloud. The Jones children were observed walking away from their father and the activities during the time that the father read the instructions in the application to himself. In contrast, the father in the Philips family held the phone throughout the session, but read aloud the instructions to his children, and helped them to follow them, for example, by prompting them to think more about the details of the leaves:

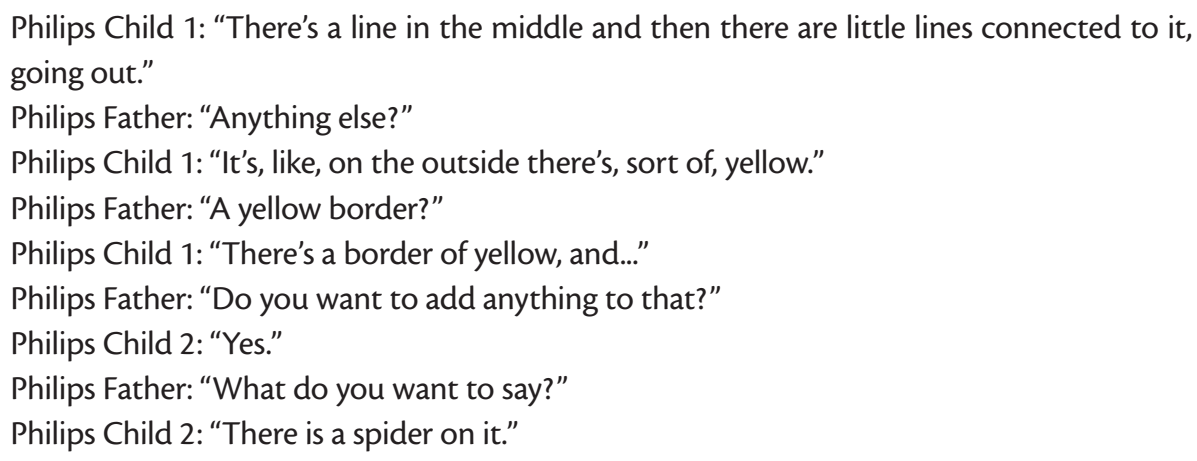

The mother of the Reid family only took control of the phone during moments that she felt required clarification, but readily put the phone back into the hands of the children. The Reid children gathered around the device and made efforts to promote sharing the phone throughout the program by handing the phone to siblings, and allowing siblings to see the screen display at the same time as the person holding the phone. The fact that a single handheld was shared by a family complicates the ability to observe autonomy because children were allowed differing levels of autonomy by parents and they often shared the device; however, it was apparent that when children were given control of the phone, they demonstrated feeling a strong sense of autonomy. Such demonstrations included determining which direction to turn, leading the rest of the family through a learning module, and making choices during learning modules. During these demonstrations, the children appeared confident and excited. When children were asked what they liked most about SunDial, in both interviews and questionnaires, they repeatedly said the phone itself was their favorite part of the program, suggesting that having the device was a key component of their sense of autonomy. Further, these feelings of autonomy and engagement were best supported by strategies where the device was either truly shared among family members, or given to the children to control. This suggests that designs for these systems might bene- 
fit from explicitly suggesting appropriate patterns of sharing the device, for instance, asking the family to allow each person to use it for part of a group task.

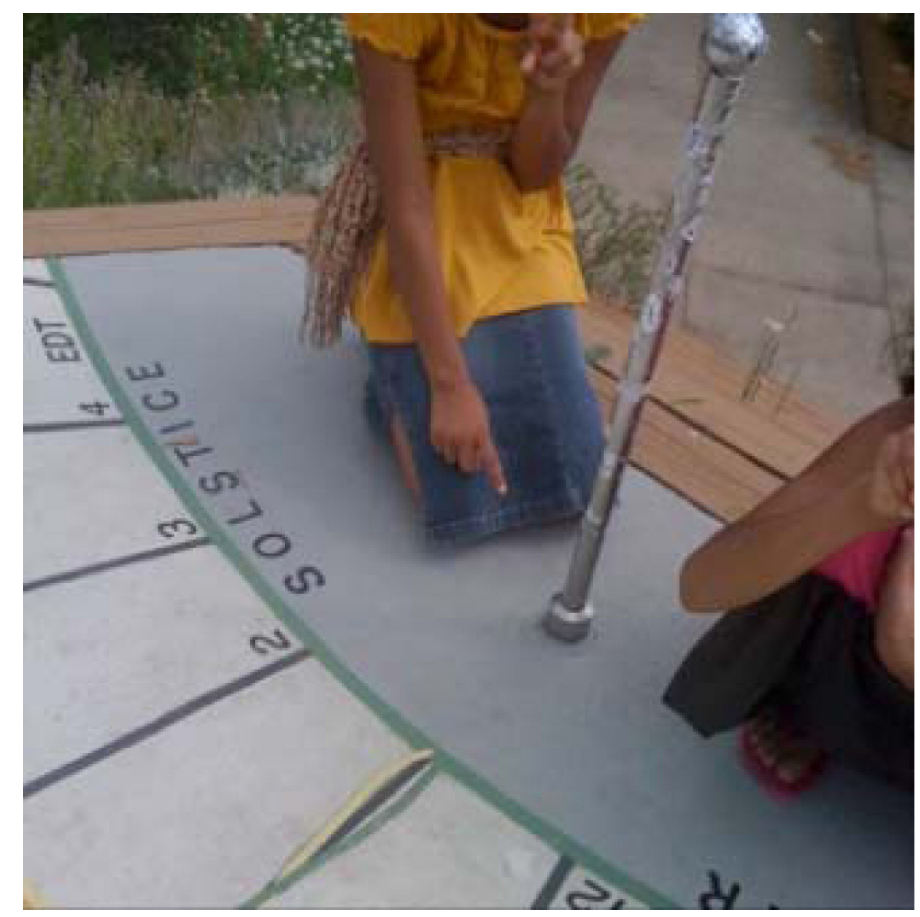

Figure 2. Participants at the Sun Dial, in a picture captured by the family during the Sundial Challenge.

\section{Learning through navigation}

Though 32 of 36 participants said they knew how to read a map, only six had previously used a handheld device to navigate. Thus, for many families the navigation itself was a challenge, and the GPS itself was sometimes inaccurate. However, these problems did not discourage families. The Reid children remarked that the hardest thing about SunDial was trying to follow the map, but quickly added that they "got used to it". The feedback from the moving blue dot kept the family's interest and prompted them to continue trying. A Phillips child said, "sometimes it (the module) is not really where the dot is" to which the father replied, "you have to interpret where it is." Indeed, the more time they spent lost, the greater their visible excitement when they found their way: when the Reid children became confident they were on the right track and saw their destination, they joyfully sprinted toward it, loudly cheering about their success.

This example shows that navigating was a "safe" way for children and families to "fail" without the stigma attached to failure. Though several families experienced some frustration when they were lost for more than about five minutes, most enjoyed the experience. In addition, the trial and error nature of their navigation mirrors the scientific process, and encourages spatial thinking (Downs, 2006). This aspect of the study shows much promise, 
suggesting that navigation as a teaching tool and method of engagement merits further exploration.

\section{Two-Way Engagement With Science}

SunDial clearly succeeded in producing the kinds of engagement suggested by the NRC report (Bell et al., 2009). Parents' responses to questionnaires indicated that they recognized their children engaged in observation and deduction, reading maps, responding to questions, and exploration; in other words, they were engaged in the kinds of inquiry and reasoning described in Strand 3 of the indicators (manipulate, test, explore, predict, question, observe, and make sense of the natural and physical world). Observers at all three modules also saw evidence of this kind of engagement. At the sundial, participants often pointed and moved quite a bit in order to understand the movements of the sun and the Earth. At the leaf and water modules, the final "why" questions often prompted intense contemplation followed by conversation as families tried to reason out the answers.

Reid Child 3 [at the water module]: "I think the water moves that way because there are fishes in the lake...oh, and because the wind is strong enough to move it that way."

Philips Father [at the leaf module]: "Different leaves are different shapes, right?

Philips Child 2: "Well, some leaves are shaped crooked because caterpillars or slugs ate them."

Philips Child 1: "Hey, I was gonna say that!"

We also saw indications of collaborative work (Strand 5: participate in scientific activities and learning practices with others, using scientific language and tools) in many groups. Almost every family collaboratively worked to predict where the sundial's shadow would be in the winter. Often we saw one family member crouching and pointing to the current shadow while another member stood where their shadow would have been. During the whole program, the Reids made multiple efforts to share the phone and to take turns providing answers to the application, supporting each child's excitement at the prospect of using a smart phone despite each child's strong desire to hold the device.

Finally, there was a clear sense of learners' agency (Strand 6: think about themselves as science learners and develop an identity as someone who knows about, uses, and sometimes contributes to science), and demonstrable evidence that participants were reflecting on their own processes of learning science (Strand 4: reflect on science as a way of knowing; on processes, concepts, and institutions of science; and on their own process of learning about phenomena). One child said she "got to act like a scientist", a common theme in children's responses. The Reid children repeatedly referred to the program as a series of challenges that they overcame. The design emphasized the idea that learners were engaged as scientists from the beginning of the experience as the tutorial asked them to record their beliefs about what scientists do and their mental images of what a scientist looked like. Nearly all families said that scientists wear white lab coats and glasses, and many remarked 
that scientists "observe", "research", "invent", "explore", "build", "create", and "discover", themes that resurfaced in participants' responses about their own activities during the final reflection questions:

\footnotetext{
"We made scientific observations of (the leaf)."

"We explored the environment also using technology...the iPhone...by doing dances and making observations."

"It was discovery...encountering new things and how they work."
}

Overall, the families' reactions suggested that the program accomplished its goals of supporting engaged ISE experiences and supporting social and meaningful experiences. From finding the next activity to observing, describing, and reasoning about the phenomena presented by the learning modules, SunDial appeared to engage groups of participants in ways that the strands suggest lead to effective, meaningful informal science education. While part of the attraction may have been the phone itself (as children reported), both our observations and participants' self-reports suggest that the focus was on the activities and the learning, and not the phone or the study itself.

\section{Other observations}

In addition to participants' reactions to the four main features and their engagement in ISE activities, we observed several other themes about people's use of SunDial that might inform the design of related handheld technologies for ISE.

\section{The dynamics of sharing}

Like Hope et al. (2009), we found that dynamics around sharing the handheld were an important part of the experience. Children were often engaged in the experience even when parents were holding the phone, as long as the parents used strategies such as reading aloud and explicit sharing of the phone. We think this is because the activities, including observing, thinking, drawing, dancing, and posing for pictures, gave children a way to collaborate and be engaged without the device being the star of the show.

The dynamics were different when other children controlled the phone; if the holder read aloud, the others tended to remain engaged, but if the activity depended on using the phone, the other children who were not using the phone would sometimes lose interest. Our observations also suggest that there was a greater chance of disengagement if there were large age gaps between the controller and the other children, or if the other children were of a different gender. Families in which either the parents or the children themselves explicitly rotated control of the handheld between children for each module, such as the Reid children, were more engaged throughout the program. So were families where the parents were engaged but not necessarily in control, as with parents who knew the direc- 
tion of the next module and who would provide hints to the children (rather than leading the way).

\section{The distraction of visual instructions}

We believe we made a design mistake regarding the presentation of instructions for the learning modules. Although the handhelds asked the learners to provide field notes using a number of media, the phone itself provided all instructions visually, using text for the questions and module descriptions and a map for navigation. This may have been a mistake, as guides that use text can distract people from museum exhibits (Cosley et al., 2009). Some groups occasionally lost interest in reading, leading to mishaps in following directions. In addition, one family said they would like the phone to make sounds or play music. Providing audio instructions instead might have further supported engagement with the learning activities themselves.

\section{Presentation of self}

Families often discussed and practiced their answers, or did multiple "takes" of audio recordings and pictures. They also often over-articulated their answers when making audio recordings. These kinds of rehearsals indicate the families were formally presenting themselves. This may be because the families were aware that they were being watched and taped, but it was an unexpected aspect of asking people to record their observations using multiple media, and could prove interesting in future research on projects like SunDial.

\section{Conclusion}

This study points to a number of useful considerations around the design of museum technologies that support informal science education. Using handhelds to breach the boundary of the museum allowed us to create engaging ISE experiences that would be difficult to replicate in most museums. Mobility also supported the use of navigation as both an educational tool in and of itself and as a way to provide both guidance and autonomy to learners. However, many designs for mobile technology assume the device belongs to a single user; this assumption is often false in museum and educational settings, and as we saw, when handhelds are used by groups, issues of access, control, and sharing of the technology arise that can affect learners' autonomy and engagement. Designs can also err by requiring too much attention-as Sundial did, through presenting its instructions as text-which can harm engagement.

More generally, our experience demonstrates the value of explicitly using pedagogical guidelines, such as the recent NSF and NRC reports on supporting informal science education and the New York State Curriculum and Instruction Guide in Science, as resources in the design of these technologies. We tried hard to tie the specific goals and features of the device to objectives and activities specified by these guidelines, and although we do not 
have direct measures of learning, we do have good evidence that the technology supported engagement with informal science education. Our experience suggests that museums, science centers, and other venues that promote informal science education might also benefit from careful attention to these guidelines when designing exhibits and technologies to support them.

\section{References}

Bell, G. \& Gemmell, J. (2009). Total recall: How the e-memory revolution will change everything. New York, NY: Dutton.

Bell, G. (2002). Making sense of museums: The museum as 'cultural ecology'. Intel Labs, 1.

Bell, P., Lewenstein, B.V., Shouse, A.W., \& Feder, M. (2009). Learning science in informal environments: People, places, and pursuits. Washington, DC: National Academies Press.

Boud, D., Keogh, R., \& Walker, D. (1985). Reflection: Turning experience into learning (1 ed.). Routledge.

Chavez, D.J., Schneider, I., \& Powell, T. (2004). The social-psychology of a technology driven outdoor trend: Geocaching in the USA. In Proceedings of HICSS.

Chipman, G., Druin, A., Beer, D., Fails, J. A., Guha, M.L., \& Simms, S. (2006). A case study of tangible flags: A collaborative technology to enhance field trips. In Proceedings of the 2006 conference on interaction design and children. Tampere, Finland.

Clough, G., Jones, A.C., McAndrew, P., \& Scanlon, E. (2008). Informal learning with pdas and smartphones. Journal of Computer Assisted Learning, 24(5), 359-371.

Cosley, D., Baxter, J., Lee, S., Alson, B., Nomura, S., Adams, P., Sarabu, C., \& Gay, G. (2009). A tag in the hand: Supporting semantic, social, and spatial navigation in museums. In Proceedings of the 27th international conference on human factors in computing systems. Boston, MA: ACM.

Dourish, P. (2004). Where the action is: The foundations of embodied interaction. Cambridge, MA: The MIT Press.

Downs, R. \& DeSouza, A. (2006). Learning to think spatially: GIS as a support system in the K-12 curriculum. Washington, DC: National Research Council and National Academies Press.

Friedman, A. (2008). Framework for evaluating impacts of informal science education projects. Washington, DC: National Science Foundation.

Grinter, R.E., Aoki, P. M., Szymanski, M.H., Thornton, J.D., Woodruff, A., \& Hurst, A. (2002). Revisiting the visit: Understanding how technology can shape the museum visit. In Proceedings of the 2002 ACM conference on computer supported cooperative work. New Orleans, LA.

Hope, T., Nakamura, Y., Takahashi, T., Nobayashi, A., Fukuoka, S., Hamasaki, M., et al. (2009). Familial collaborations in a museum. In CHI '09: Proceedings of the 27th international conference on human factors in computing systems. ACM.

Hsi, S. \& Fait, H. (2005). RFID: Tagging the world-rfid enhances visitors' museum experience at the exploratorium. Communications of the Acm-Association for Computing Machinery-Cacm, 48(9), 60-65.

New York State Curriculum and Instruction Guide in Science. (2009). (New York State Learning Standards). New York: NYSED. Retrieved August 31, 2010, from http://www.emsc.nysed.gov/ciai/mst/mstls.html

O'Hara, K. (2008). Understanding geocaching practices and motivations. In Proceeding of the twenty-sixth annual SIGCHI conference on human factors in computing systems. 
Parr, C.S., Jones, T., \& Songer, N. B. (2004). Evaluation of a handheld data collection interface for science learning. Journal of Science Education and Technology, 13(2), 233-242.

Rennie, L.J. \& McClafferty, T. P. (1996). Science centres and science learning. Studies in Science Education, 27(1), 53-98.

Tallon, L., \& Walker, K. (2008). Digital technologies and the museum experience: Handheld guides and other media. Lanham: Rowman Altamira.

Thom-Santelli, J., Toma, C., Boehner, K., \& Gay, G. (2006). Beyond just the facts: Museum detective guides. $\mathrm{HCl}$ Group, Cornell University. Retrieved January, 26, 2006.

\section{Notes}

1. The names of the families have been changed to maintain anonymity.

Megan Halpern, MS

PhD Student

Department of Communication

Cornell University, Ithaca, NY, US

mkh46@cornell.edu

Max Evjen, MBA

Graduate Student

Department of Museum Studies

Johns Hopkins University, Washington, DC, US

devjen1@jhu.edu

Dan Cosley, PhD

Assistant Professor

Department of Information Science

Cornell University, Ithaca, NY, US

danco@cs.cornell.edu

Michael Lin, BS

Student

Information Science, Systems, and Technology

Cornell University, Ithaca, NY, US

mc176@cornell.edu 
M. Halpern, M. Evjen, D. Cosley, M. Lin, S. Tseou, E. Horowitz, S.T. Peesapati \& G. Gay MedieKultur 50 Article: SunDial: Embodied informal science education using GPS

Stephen Tseou, BS

College of Engineering

Cornell University, Ithaca, NY, US

skt25@cornell.edu

Erica Horowitz

Student

Information Science, Systems, and Technology

Cornell University, Ithaca, NY, US

elh75@cornell.edu

S. Tejaswi Peesapati, MS

Usability Research Specialist

Oracle Corporation, Pleasanton, CA, US

me@sivatejaswi.com

Geri Gay

Kenneth J. Bissett Professor and Chair

Department of Communication

Cornell University, Ithaca, NY, US

gkg1@cornell.edu 